\title{
POLÍTICA EXTERIOR Y DERECHOS HUMANOS DURANTE EL SEXENIO DE ENRIQUE PEÑA NIETO ${ }^{1}$
}

\author{
FOREIGN POLICY AND HUMAN RIGHTS DURING THE \\ ADMINISTRATION OF ENRIQUE PEÑA NIETO
}

\author{
LA POLITIQUE ÉTRANGÈRE ET LES DROITS DE \\ L'HOMME SOUS LE GOUVERNEMENT \\ D'ENRIQUE PEÑA NIETO
}

\author{
Alejandro Anaya Muñoz \\ ITESO, Universidad Jesuita de Guadalajara \\ aanaya@iteso.mx
}

\begin{abstract}
Resumen: Este artículo describe la política exterior de derechos humanos desplegada durante el sexenio de Enrique Peña Nieto (2012-2018). Para ello, rastrea tanto las acciones del gobierno mexicano mediante las cuales se ha buscado incidir en procesos externos, como las orientadas a contener las influencias internacionales en las dinámicas internas del país. Desde una perspectiva analítica, el artículo explora las tendencias de continuidad o cambio y concluye que el periodo se caracteriza por tensiones y contradicciones. Por un lado, se han mantenido tanto el activismo en foros multilaterales como la política de apertura al escrutinio internacional, mientras que, por el otro, se han presentado señales que sugieren intentos por volver a un acercamiento basado en la soberanía y la no intervención.
\end{abstract}

Palabras clave: política exterior; México; derechos humanos;

Enrique Peña Nieto; apertura; órganos internacionales de derechos humanos.

Aвstract: This article describes the human rights-oriented foreign policy deployed during the administration of Enrique Peña Nieto (2012-2018). To do this, it traces both the actions of the Mexican government that sought to

${ }^{1}$ Agradezco la extraordinaria asistencia de Paula Martínez Valencia en esta investigación. 
influence external processes, and those aimed at containing international influences on the internal dynamics of the country. From an analytical perspective, the article explores trends of continuity or change and concludes that the period is characterized by both tensions and contradictions. On the one hand, activism in multilateral forums and the policy of opening up to international scrutiny have been maintained, while on the other hand there have been signs that suggest attempts to return to an approach based on sovereignty and non-intervention.

Keywords: foreign policy; Mexico; human rights; Enrique Peña Nieto; opening up; international human rights bodies.

\section{Traducción de Gonzalo Celorio Morayta}

RÉsumé: L'article esquisse la politique étrangère concernant les droits de l'homme qu'a déployée le gouvernement d'Enrique Peña Nieto. On identifie les mesures du président qui cherchaient à agir sur le plan international, aussi bien que d'autres dont le but était de limiter l'influence de l'extérieur sur la vie interne du Mexique. Le texte essaie d'établir ce qui favorise soit la continuité, soit le changement, et il aboutit à la conclusion que la période analysée a été marquée par des tensions et des contradictions. Le Mexique a gardé une attitude militante aux tribunes multilatérales et il est resté ouvert à la surveillance internationale; cependant, il a laissé entrevoir aussi le désir d'affirmer, comme autrefois, les principes de souveraineté et de non-intervention.

Mots clefs: Mexique; droits de l'homme; Enrique Peña Nieto; ouverture; organisations internationales pour les droits de l'homme.

Traducción de BERNARDo Mabire

Fecha de recepción: diciembre de 2018

Fecha de aceptación: febrero de 2019 


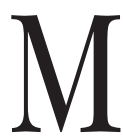
ÉXICO figuró entre los países que, tras el fin de la Segunda Guerra Mundial, pugnaron por una inclusión más significativa de los derechos humanos dentro de la nueva estructura de organización internacional. ${ }^{2}$ Sin embargo, tras la adopción de la Declaración Americana de Derechos y Deberes del Hombre y de la Declaración Universal de Derechos Humanos, en 1948, México solamente mostró un compromiso retórico con tales derechos y con el naciente régimen internacional en la materia. El país fue muy cauto en la ratificación de los tratados multilaterales que en este campo fueron surgiendo, tanto en el marco de la Organización de las Naciones Unidas (ONU) como de la Organización de los Estados Americanos (OEA) y más precavido aun en reconocer la competencia o jurisdicción de los incipientes órganos internacionales para recibir quejas individuales sobre casos concretos de violaciones a los derechos humanos. Asimismo, en términos generales, México evitó criticar la situación de estos derechos en otros países. ${ }^{3}$ En suma, durante la segunda mitad del siglo $\mathrm{xx}$, la política exterior mexicana en materia de derechos humanos se fundó en los principios de soberanía y no intervención. Fue tras la alternancia de 2000, en el sexenio de Vicente Fox (2000 a 2006), que observamos con claridad un cambio significativo, al implementarse un acercamiento basado en la apertura al escrutinio internacional y la activa participación de México en los foros multilaterales de derechos humanos. ${ }^{4}$ Esta nueva política exterior se mantuvo, en buena

${ }^{2}$ Paul Gordon Lauren, The Evolution of International Human Rights. Visions Seen, Philadelphia, University of Pennsylvania Press, 2a ed., 2003, pp. 154-187.

${ }^{3}$ Natalia Saltalamacchia Ziccardi y Ana Covarrubias Velasco, "La trayectoria de los derechos humanos en la política exterior de México (19452006)", en Natalia Saltalamacchia Ziccardi y Ana Covarrubias Velasco (eds.), Derechos humanos en política exterior. Seis casos latinoamericanos, Ciudad de México, IтAм / Miguel Ángel Porrúa, 2011, pp. 166-176.

${ }^{4}$ Loc. cit.; Alejandro Anaya Muñoz, "Transnational and domestic processes in the definition of human rights policies in Mexico", Human Rights Quarterly, 31 (2009), pp. 35-58. 
medida sin cambios, durante los sexenios de Vicente Fox y Felipe Calderón. ${ }^{5}$ ¿Cuáles han sido, entonces, las principales características de la política exterior de México en materia de derechos humanos durante el sexenio de Enrique Peña Nieto? ¿Se mantuvo la política exterior de apertura durante este sexenio, caracterizado por el regreso del Partido Revolucionario Institucional (PRI) a la Presidencia de la República?

En este artículo se entiende la política exterior como las acciones llevadas a cabo por los órganos del Estado con respecto a su entorno externo o "esfera internacional", conducidas por los canales comunes de la diplomacia o por cualquier otro medio o mecanismo oficial. ${ }^{6}$ Se parte del supuesto de que tales acciones siguen dos lógicas o dinámicas: la relacionada con los intentos del Estado por influir en los procesos internacionales (la lógica de "adentro hacia afuera”) y la que tiene que ver con el manejo de las influencias internacionales en los procesos internos del país (lógica de "afuera hacia adentro"). Por el lugar de México en la división internacional de poder, por sus dinámicas internas de derechos humanos (marcadas por graves problemas en la materia) y por las características propias de la política internacional y transnacional de los derechos humanos, la lógica dominante en su política exterior de derechos humanos es la de afuera hacia adentro. Mientras que la política exterior de una democracia desarrollada, por ejemplo, suele centrarse en la manera en que puede (o debe) influir en la situación de derechos humanos en otros países, para una nación como México la mayor parte de su energía en este ámbito se enfoca en responder o buscar manejar, o contener los intentos de actores externos por influir en los procesos internos. ${ }^{7}$

${ }^{5}$ Alejandro Anaya Muñoz, "Política exterior y derechos humanos durante el gobierno de Felipe Calderón”, Foro Internacional, vol. LIII, núms. 3-4 (2013), pp. 771-793.

${ }^{6}$ Alejandro Anaya Muñoz, Derechos humanos en y desde las relaciones internacionales, México, CIDE, 2014, p. 142.

7 Alejandro Anaya Muñoz, El país bajo presión. Debatiendo el papel del escrutinio internacional de derechos humanos sobre México, México, CIDE, 2012. 
El texto comienza describiendo el activismo de México en los foros multilaterales de derechos humanos. Posteriormente, examina las dinámicas de afuera hacia adentro: las acciones de monitoreo y escrutinio externo sobre México (visitas, informes y recomendaciones por parte de órganos internacionales especializados en derechos humanos) y las tensiones entre el gobierno de Enrique Peña Nieto (EPN) y distintos órganos a raíz de ciertos procedimientos internacionales. Se concluye con una reflexión sobre la continuidad y el cambio en la política exterior del país en materia de derechos humanos. El argumento final es que si bien se identifican señales claras de continuidad en la política de apertura, también se encuentran otras que sugieren tensiones y el posible resurgimiento de un acercamiento basado en la soberanía y la no intervención. El artículo concluye especulando brevemente sobre los factores que pueden explicar tanto la continuidad como las señales de cambio identificadas.

\section{Dinámicas de adentro hacia AFUera: MéXico EN LOS FOROS MULTILATERALES}

Durante los sexenios de Vicente Fox y Felipe Calderón, México participó activamente en foros multilaterales de derechos humanos, buscando contribuir al desarrollo de las normas internacionales en la materia. ${ }^{8}$ En esta misma línea, en el sexenio de EPN, uno de los objetivos centrales de la Secretaría de Relaciones Exteriores en este ámbito fue "mantener la presencia en los foros multilaterales". ${ }^{9}$

${ }^{8}$ A. Anaya Muñoz, "Política exterior...", op. cit.

9 Alejandro Anaya Muñoz, entrevista con Erasmo Lara Cabrera, director general de Derechos Humanos y Democracia de la Secretaría de Relaciones Exteriores, 18 de mayo de 2018; Erasmo A. Lara Cabrera, "Política exterior multilateral, derechos humanos y grupos en situación de vulnerabilidad", Revista Mexicana de Política Exterior, núm. 110 (2017), pp. 97-117. 
Por ejemplo, México fue electo para ser uno de los 47 Estados miembros del Consejo de Derechos Humanos (CDH) de la ONU, durante el periodo de 2014 a 2016 y repitiendo nuevamente en 2018. Es importante notar que desde la creación del CDH en 2006, la pertenencia de México ha sido constante, ausentándose únicamente en 2013 y en 2017, en virtud de la regla que solamente permite una reelección inmediata a los Estados miembros. No obstante, en esos dos años, México mantuvo su participación como "Estado observador", por lo que a lo largo de todo el sexenio participó activamente en todas las sesiones del órgano.

$\mathrm{Al}$ igual que con la administración anterior, México continuó presentando y copresentando un muy buen número de resoluciones temáticas en el CDH. En total, entre 2013 y 2017, promovió sesenta resoluciones temáticas y copromovió 97 . Por otro lado, votó a favor de la gran mayoría de resoluciones temáticas adoptadas mediante voto, absteniéndose en 19 ocasiones y votando en contra solamente en tres. Las resoluciones presentadas y copresentadas por México durante este periodo se relacionaron de manera particular con los derechos de las mujeres y la equidad de género, de las personas con discapacidad, de los pueblos indígenas, de las personas migrantes y de la niñez, y con la cuestión del terrorismo y los derechos humanos, temas que "México tradicionalmente ha abanderado". ${ }^{10}$ De esta manera, se buscó contribuir a "fortalecer los marcos internacionales de protección", particularmente en lo que respecta a los derechos de grupos sociales en situación de vulnerabilidad. ${ }^{11}$

Durante los sexenios de Fox y Calderón, las delegaciones mexicanas ante los foros multilaterales de derechos humanos comenzaron a votar a favor de resoluciones críticas con otros países. ${ }^{12}$ Esto no cambió durante el gobierno de EPN. Entre 2013 y 2017, se adoptaron en el CDH, mediante el voto,

\footnotetext{
${ }^{10}$ A. Anaya Muñoz, entrevista con Erasmo Lara..., op. cit.

${ }^{11}$ Loc. cit.

12 A. Anaya Muñoz, "Política exterior...", op. cit., pp. 780-781.
} 
un total de 52 resoluciones sobre la situación de los derechos humanos en países concretos. México respaldó prácticamente todas, absteniéndose solamente en dos, relacionadas con Bielorrusia. Más aún, durante este periodo copromovió resoluciones sobre Ucrania y Sudán del Sur. De esta manera, México continuó expresándose abiertamente de manera crítica sobre la situación en otros países, manteniendo una política exterior que dejaba atrás los principios de soberanía y no intervención.

El principal mecanismo de monitoreo de la situación de derechos humanos con que cuenta el $\mathrm{CDH}$ es el examen periódico universal (EPU), basado en un escrutinio periódico entre pares de la situación de los derechos humanos en cada uno de los Estados miembros de la onU. ${ }^{13} \mathrm{El}$ resultado final del EPU es un informe en el que se incluyen recomendaciones al Estado evaluado, elaboradas por el resto de los integrantes. Los Estados observadores también pueden participar y formular recomendaciones en el CDH. Entre enero de 2013 y noviembre de 2017, México realizó un total de 624 recomendaciones a los 192 Estados que fueron evaluados: ${ }^{14}$ un promedio de 3.2 recomendaciones por país (o por EPU-país), lo cual no significa un cambio con respecto al sexenio anterior, cuyo promedio fue de $3.14 .{ }^{15}$ En el periodo examinado, 43 recomendaciones hechas por México (el 7\% del total) fueron rechazadas por los países a las que fueron dirigidas.

13 Véase Naciones Unidas, Asamblea General, Resolución 60/251 (A/RES/60/251), 3 de abril de 2006; Naciones Unidas, Consejo de Derechos Humanos, Resolución 5/1, 18 de junio de 2007; A. Anaya Muñoz, Derechos humanos en..., op. cit., pp. 68-73.

${ }^{14}$ Se revisaron los informes elaborados entre la decimoquinta (21 de enero al 1 de febrero de 2013) y la vigésima octava sesiones (6 al 17 de noviembre de 2017). No obstante, al momento de elaborar este artículo, aún no se encontraban disponibles los informes correspondientes a Guatemala, Benín, Zambia y Japón (elaborados en la vigésima octava sesión), por lo que no fueron incluidos en el análisis.

15 A. Anaya Muñoz, "Política exterior...", op. cit., pp. 781-782. 
Esto sugiere que se han asumido posturas críticas sobre la situación de los derechos humanos en otros países. ${ }^{16}$

Finalmente, en los últimos años del gobierno de EPN, México fue "mucho más vocal"17 o abiertamente crítico con respecto a la situación política y la violación de los derechos humanos en Venezuela. Expresó "su preocupación” sobre la "crisis democrática" o el deterioro de la institucionalidad en aquel país, en un principio, subrayando los postulados de soberanía y no intervención, y la necesidad de una solución pacífica del conflicto entre los propios actores venezolanos. Hacia finales del sexenio, no obstante, las críticas mexicanas subieron de tono, al cuestionar abiertamente la legitimidad del proceso electoral de mayo de 2018, llamar a consultas a su embajadora en aquel país y emitir una alerta al sector financiero y bancario mexicano sobre los riesgos de hacer operaciones con el gobierno de Venezuela. ${ }^{18}$ Si bien los cuestionamientos o la crítica se enfocaron de manera más explícita en el tema del respeto a la institucionalidad democrática, también incluyeron críticas a la violación de los derechos humanos en sí.

Otra manera de rastrear la política exterior de México de adentro hacia afuera, con respecto a los regímenes interna-

${ }^{16}$ Ibid., p. 782.

${ }^{17}$ A. Anaya Muñoz, entrevista con Erasmo Lara..., op. cit.

${ }^{18}$ Véase, por ejemplo, Secretaría de Relaciones Exteriores, SRE, "Comunicado sobre Venezuela”, comunicado núm. 183, 3 de mayo de 2017, https://www.gob.mx/sre/prensa/comunicado-sobre-venezuela-105611 (consulta del 11 de junio de 2018); Secretaría de Relaciones Exteriores, SRE, "Situación en Venezuela", comunicado núm. 252, 28 de junio de 2017, https://www.gob.mx/sre/prensa/situacion-en-venezuela?idiom=es (consulta del 11 de junio de 2018); Secretaría de Relaciones Exteriores, SRE, "México llama a consultas a su embajadora en Venezuela" (comunicado núm. 147), 21 de mayo de 2018, https://www.gob.mx/sre/prensa/ mexico-llama-a-consultas-a-su-embajadora-en-venezuela (consulta del 11 de junio de 2018); Secretaría de Relaciones Exteriores, SRE, "Cumbre de las Américas. Declaración sobre Venezuela" (comunicado núm. 96), 16 de abril de 2018, https://www.gob.mx/sre/prensa/cumbre-de-las-americas-declaracion-sobre-venezuela (consulta del 11 de junio de 2018). 
cionales de derechos humanos, es observar sus aportaciones económicas a los órganos internacionales. Durante el periodo de EPN, el gobierno mexicano realizó importantes aportaciones voluntarias a la Corte Interamericana de Derechos Humanos (Corte IDH) y a la Comisión Interamericana de Derechos Humanos (CIDH). En total, entre 2013 y 2017, México aportó un total de 1775000 dólares a la Corte IDH y de 3245100 dólares a la CIDH. Esto equivale al 15\% de los ingresos extraordinarios captados por la primera y a $13 \%$ de los "fondos específicos" de la segunda en el periodo.

A finales del sexenio de Felipe Calderón y durante los primeros meses del gobierno de EPN, México fue un actor protagónico en un proceso regional de discusión sobre la reforma de la CIDH, iniciado por países como Ecuador, Brasil y la propia Venezuela. Cabe recordar que en aquel periodo esos Estados cuestionaron a la CIDH y pusieron en marcha un proceso de discusión diplomática que esperaban resultara en el acotamiento de su autonomía y sus funciones de escrutinio. México, en conjunto con otros países, se enfocó en una discusión más técnica encaminada a mejorar algunas de los procedimientos de la CIDH, a la vez que daba un fuerte respaldo político a su autonomía y las funciones que venía desempeñando. ${ }^{19}$ En otras palabras, se mostró como un aliado confiable de la CIDH. No obstante, como se aborda con mayor detalle en la siguiente sección, conforme avanzó el sexenio se empezaron a dar tensiones importantes entre el gobierno mexicano y esta comisión. La etapa de mayor tensión coincidió con un difícil periodo de crisis financiera del organismo, en 2016. En este marco, México comenzó a cuestionar "la confiabilidad e imparcialidad de la CIDH" y, en la sesión ordinaria del Consejo Permanente de la oeA del 25 de mayo de dicho año, argumentó "que la 'selectividad' en cuanto al tratamiento de ciertos casos o denuncias, su politi-

19 Alejandro Anaya Muñoz y Natalia Saltalamacchia Ziccardi, "México y la reforma al Sistema Interamericano de Derechos Humanos", Pensamiento Propio, núm. 38 (2013), pp. 49-88. 
zación y parcialidad en ciertos temas y países, así como su falta de «criterio uniformado» constituían motivos suficientes para dejar de confiar en la CIDH y, por lo tanto, dejar de apoyarla financieramente". ${ }^{20}$

Durante los dos sexenios anteriores al de EPN, el gobierno promovió muy activamente el nombramiento de mexicanos como integrantes de los órganos internacionales de derechos humanos. ${ }^{21}$ Después, durante el primer año de la administración priista, se continuó con este acercamiento, proponiendo expertos nacionales (principalmente académicos) para formar parte del Comité contra la Desaparición Forzada y la CIDH. ${ }^{22}$ Sin embargo, a partir de 2015, el gobierno cambió la ruta, promoviendo la candidatura de diplomáticos de carrera.

En 2015, México había propuesto al académico Miguel Sarre (ampliamente reconocido a nivel internacional por sus conocimientos en materia de tortura y por haber fungido ya como miembro del Subcomité para la Prevención de la Tortura de la onu) para ocupar un lugar en el Comité contra la Tortura de la onU. Sin embargo, posteriormente, y de manera controversial, el gobierno retiró esta candidatura y presentó en su lugar al embajador emérito Claude Heller. Posteriormente, en 2017, el gobierno decidió no presentar al académico Santiago Corcuera para un segundo periodo como miembro del Comité contra la Desaparición Forzada de la onu. Esta decisión fue incluso más controvertida, pues Corcuera no solamente ya era miembro del Comité (que bus-

${ }^{20}$ Olga Guzmán Vergara, "México y su política exterior de negación. La defensa de derechos humanos en un contexto de retrocesos", SUR. Revista internacional de derechos humanos, vol. 14, núm. 26 (2017), pp. 89-102.

${ }^{21}$ Alejandro Anaya Muñoz, entrevista con Santiago Corcuera Cabezut, 7 de mayo de 2018; A. Anaya Muñoz, "Política exterior...", op. cit.

22 Secretaría de Relaciones Exteriores, SRE, Primer informe de labores 2012-2013, México, SRE, 2013, p. 87. El gobierno mexicano nominó a Santiago Corcuera Cabezut para el Comité contra la Desaparición Forzada y a José de Jesús Orozco para la cidH. 
caba continuar por un segundo periodo de cuatro años), sino que era su presidente. La polémica continuó cuando el gobierno de México apoyó activamente la postulación del embajador Joel Hernández (miembro en activo del Servicio Exterior Mexicano en ese momento) para integrarse a la CIDH. ${ }^{23}$

\section{DinÁMICAS DE AFUERA HACIA ADENTRO: RESPUESTAS Y TENSIONES ANTE LA PRESIÓN INTERNAGIONAL}

\section{El monitoreo externo: visitas, informes y recomendaciones}

En el sexenio de EPN, México mantuvo la "invitación abierta y permanente" a los órganos internacionales de derechos humanos para que visitaran el país, establecida desde 2001 por el gobierno de Fox. Entre 2013 y 2017, se realizaron catorce visitas de investigación in loco. ${ }^{24}$ Como referente, en el sexenio anterior también se dieron 16 visitas de este tipo, por lo que podemos observar continuidad en esta manifestación de la política de apertura. ${ }^{25}$ Es importante destacar también los numerosos viajes al país de los integrantes del Grupo Interdisciplinario de Expertos Independientes (GIEI), grupo ah hoc establecido por la CIDH para proporcionar asistencia técnica a México en la investigación de la desaparición de los 43 estudiantes de la normal rural Raúl Isidro Burgos, de Ayotzinapa, Guerrero. El papel del GIEI y

23 A. Anaya Muñoz, entrevista con Santiago Corcuera..., op. cit. Al momento de terminar la elaboración de este artículo, se dio a conocer la selección de la mexicana Amalia Eva Gamio Ríos como integrante del Comité de Derechos de las Personas con Discapacidad de la onU. En 2018 se terminará el actual periodo de Eduardo Ferrer Mac-Gregor, como juez de la Corte IDH (actualmente, presidida por él). Se espera que el gobierno mexicano apoye su nombramiento para un segundo periodo como miembro de la corte.

${ }^{24}$ Una de ellas fue una visita conjunta de los relatores sobre la libertad de expresión de la onu y de la oEA, en 2017.

25 A. Anaya Muñoz, "Política exterior...", op. cit., pp. 775-777. 
su complicada interacción con el gobierno mexicano se explora más adelante. ${ }^{26}$

En este marco de visitas, así como de revisión de los informes periódicos que México tiene que presentar ante los órganos de tratados de la onu, entre 2013 y 2017 el país fue objeto directo de un total de catorce informes de monitoreo, en los cuales se plasmaron un total de 919 recomendaciones, un número no muy diferente a las recibidas en el sexenio previo. $^{27}$

Entre estos informes destacan, por la polémica que generaron y la reacción defensiva o de "negación"28 con que respondió el gobierno mexicano, el informe de 2014 del relator especial contra la tortura de la oNU, ${ }^{29}$ el informe de 2015 del Comité contra la Desaparición Forzada de la onU, ${ }^{30}$ el informe de país publicado por la CIDH a finales de $2015^{31}$ y los dos

${ }^{26}$ El mandato del GIEI incluyó la "elaboración de planes de búsqueda en vida de las personas desaparecidas; análisis técnico de las líneas de investigación para determinar responsabilidades penales; y análisis técnico del Plan de Atención Integral a las Víctimas", de acuerdo con la Comisión Interamericana de Derechos Humanos, $\mathrm{CIDH}$, Ayotzinapa (sitio de internet), http://www.oas.org/es/cidh/actividades/giei.asp (consulta del 24 de abril de 2018).

${ }^{27}$ En el sexenio de Felipe Calderón, México recibió un total de 927 recomendaciones de los órganos internacionales de derechos humanos. Véase Recomendaciones internacionales a México en materia de derechos humanos (sitio de internet), www.recomendacionesdh.mx

${ }^{28}$ Stanley Cohen, "Government Responses to Human Rights Reports: Claims, Denials, and Counterclaims”, Human Rights Quarterly, 18 (1996), pp. 517-543.

${ }^{29}$ Naciones Unidas, Consejo de Derechos Humanos, Informe del Relator Especial sobre la tortura y otros tratos o penas crueles, inhumanos o degradantes, Juan E. Méndez. Adición. Misión a México (A/HRC/28/68/Add.3), 29 de diciembre de 2014.

${ }^{30}$ Naciones Unidas, Comité contra la Desaparición Forzada, Observaciones finales sobre el informe presentado por México en virtud del artículo 29, párrafo 1, de la Convención (CED/C/MEX/CO/1), 5 de marzo de 2015

${ }^{31}$ Comisión Interamericana de Derechos Humanos, Situación de los Derechos Humanos en México (OEA/Ser.L/V/II. Doc. 44/15), 31 de diciembre de 2015 . 
informes sobre el caso Ayotzinapa elaborados por el GIEI, en 2015 y $2016 .{ }^{32}$

Entre 2013 y 2016, la CIDH recibió un total de 2856 peticiones (o "denuncias") sobre la presunta violación de derechos humanos en México. ${ }^{33} \mathrm{El}$ número de peticiones fue muy significativo desde una perspectiva comparada: $33 \%$ del total de peticiones recibidas en ese periodo por la CIDH fueron sobre casos que ocurrieron en suelo mexicano. ${ }^{34}$

Entre 2013 y 2017, la CIDH adoptó 26 informes de admisibilidad y cuatro de inadmisibilidad sobre peticiones recibidas de casos en México. Esto implica que, durante el gobierno de EPN, 26 casos avanzaron dentro del proceso cuasijurisdiccional de la CIDH hacia un posible informe de fondo, en el cual este organismo eventualmente se pronunciaría sobre la violación de derechos humanos en México. En el sexenio, por otro lado, la CIDH logró resolver solamente una petición mediante el procedimiento de acuerdo de solución amistosa, ${ }^{35}$

${ }^{32}$ Grupo Interdisciplinario de Expertos Independientes, GIEI, "Informe Ayotzinapa. Investigación y primeras conclusiones de las desapariciones y homicidios de los normalistas de Ayotzinapa", https://drive.google. $\mathrm{com} /$ file/d/0B1ChdondilaHNzFHaEs3azQ4Tm8/view (consulta del 20 de noviembre 2018); Grupo Interdisciplinario de Expertos Independientes, GIEI, "Informe Ayotzinapa II. Avances y nuevas conclusiones sobre la investigación, búsqueda y atención a las víctimas", https://drive.google. com/file/d/0B3wuz7S3S9urNFFlZUNMSldQUlk/view, (consulta del 20 de noviembre 2018).

${ }^{33}$ Es importante tener en cuenta que el hecho de que la cIDH reciba una petición no implica una eventual decisión positiva sobre su admisibilidad ni mucho menos sobre sus méritos. En otras palabras, esto no quiere decir que cada petición recibida equivalga a una violación confirmada de los derechos humanos.

${ }^{34}$ En el mismo sentido que la nota al pie anterior, esto no implica, por supuesto, que, por ejemplo, se hayan dado en México el 39\% de las violaciones de los derechos humanos ocurridas en todo el hemisferio durante 2014.

${ }^{35}$ Caso "Ananías Laparra Martínez y familiares", Comisión Interamericana de Derechos Humanos, Informe No. 15/16. Petición 1171-09. Informe de Solución Amistosa. Ananías Laparra Martínez y Familiares. México, OEA/Ser.L/V/II.157 Doc.19, 14 de abril de 2016, https://www. oas.org/es/cidh/decisiones/2016/MXSA1171-09ES.pdf 
adoptó tres informes de fondo ${ }^{36}$ y remitió tres casos a la Corte IDH. ${ }^{37}$

Entre 2013 y 2017, la Corte adoptó cuatro sentencias condenatorias en contra de México. ${ }^{38}$ Asimismo, mantuvo

36 Casos "Paloma Angélica Escobar Ledezma y otros", Comisión Interamericana de Derechos Humanos, Informe No. 51/13. Caso 12.551. Paloma Angélica Escobar Ledezma y Otros. Fondo (Publicación) México, 12 de julio de 2013, https://www.oas.org/es/cidh/docs/anual/2013/ docs-es/62.MXPU12551ES.pdf ; “J.S.C.H. y M.G.S.”, Comisión Interamericana de Derechos Humanos, Informe No. 80/15. Caso 12.689. Informe de Fondo (Publicación) J.S.C.H y M.G.S México, OEA/Ser.L/V/II.156 Doc. 33, 28 de octubre de 2015, https://www.oas.org/es/cidh/decisiones/2015/mxPU12689Es.pdf y "Gilberto Jiménez Hernández y otros", Comisión Interamericana de Derechos Humanos, Informe 51/16. Caso 11.564. Informe de Admisibilidad y Fondo (Publicación). Gilberto Jiménez Hernández y Otros (La Grandeza). México, OEA/Ser.L/V/II.159 Doc. 60, 30 de noviembre de 2016, https://www.oas.org/es/cidh/decisiones/2016/MXPU11564ES.docx

37 Casos "García Cruz y Sánchez Silvestre”, remitido en 2013, Comisión Interamericana de Derechos Humanos, Informe No. 138/11. Caso 12.288. Juan García Cruz y Santiago Sánchez Silvestre. Fondo. México, 31 de octubre de 2011, https:/ / www.oas.org/es/cidh/decisiones/corte/12.2 88FondoEsp.doc ; "Alvarado Espinosa”, remitido en 2016, Comisión Interamericana de Derechos Humanos, Informe No. 3/16. Caso 12.916. Informe de Fondo. Nitza Paola Alvarado Espinoza, Rocío Irene Alvarado Reyes, José Ángel Alvarado Herrera y Otros. México, OEA/Ser.L/V/II.157 Doc. 7, 13 de abril de 2016, https:/ / www.oas.org/es/cidh/decisiones/corte/ 2016/12916FondoEs.pdf y "Mariana Selvas Gómez y otras" (conocido como el caso de "las mujeres de Atenco"), también remitido en 2016, Comisión Interamericana de Derechos Humanos, Informe No. 74/15. Caso 12.846. Informe de Fondo. Mariana Selvas Gómez y Otras. México, OEA/ Ser.L/V/II.156 Doc. 27, 28 octubre de 2015, https://www.oas.org/es/ cidh/decisiones/corte/2016/12846FondoEs.pdf

38 Casos "García Cruz y Sánchez Silvestre", Corte Interamericana de Derechos Humanos, Caso García Cruz y Sánchez Silvestre vs. Estados Unidos Mexicanos. Sentencia de 26 de noviembre de 2013 (Fondo, Reparaciones y Costas), http:/ /www.corteidh.or.cr/docs/casos/articulos/seriec_ 273_esp.pdf ; "Trueba Arciniega”, Corte Interamericana de Derechos $\mathrm{Hu}-$ manos, Caso Trueba Arciniega y Otros vs. México. Sentencia de 27 de noviembre de 2018, http://www.corteidh.or.cr/docs/casos/articulos/seriec _369_esp.pdf, “Alvarado Espinosa”, Corte Interamericana de Derechos Humanos, Caso Alvarado Espinoza y Otros vs. México. Sentencia de 28 de 
seguimiento cercano de la implementación de sus sentencias previas, adoptando ocho resoluciones de supervisión de cumplimiento. El balance fue mixto: $39 \%$ de las medidas de reparación ordenadas por la Corte IDH se cumplieron, $11 \%$ se cumplieron en forma parcial y la mitad quedaron incumplidas. Es importante enfatizar que el tipo de medidas en que la Corte encuentra mayor cumplimiento es en las relativas al pago de una compensación o indemnización a las víctimas de violaciones de sus derechos humanos, mientras que el tipo de medidas que menos se cumplen son las relacionadas con la adopción de "medidas de no repetición” (lo cual incluye reformas legislativas e institucionales y, sobre todo, acciones de investigación, sanción y castigo).

El pleno de la CIDH realizó una visita in loco a México en 2015, la cual llevó a la elaboración de un informe de país, publicado a finales del mismo año. ${ }^{39}$ Este tipo de visitas y la elaboración de los informes respectivos es muy significativa, al sugerir la visión que tiene la propia CIDH sobre la gravedad de la situación de los derechos humanos en un país determinado. ${ }^{40}$ En el caso de México, la Comisión solamente había realizado una visita de este tipo en 1996, en el marco de la gran atención que generó la situación de los derechos humanos en torno al conflicto armado en

noviembre de 2018 (Fondo, Reparaciones y Costas), http://www.corteidh.or.cr/docs/casos/articulos/seriec_370_esp.pdf y caso "Mujeres Víctimas de Tortura Sexual en Atenco", Corte Interamericana de Derechos Humanos, Caso Mujeres Víctimas de Tortura Sexual en Atenco vs. México. Sentencia de 28 de noviembre de 2018 (Excepción Preliminar, Fondo, Reparaciones y Costas), http:/ / www.corteidh.or.cr/docs/casos/articulos/ seriec_371_esp.pdf

39 Comisión Interamericana de Derechos Humanos, CIDH, Informe sobre la situación de los derechos humanos en México, OEA/Ser.L/V/II. Doc. 44/15, 31 diciembre 2015, http:/ / www.oas.org/es/cidh/informes/pdfs/ mexico2016-es.pdf

40 Véase Comisión Interamericana de Derechos Humanos, CIDH, Informes de país (sitio de internet), http://www.oas.org/es/cidh/infor mes/pais.asp (consulta del 21 de abril de 2018). 
Chiapas. ${ }^{41}$ Entre otras cosas, la CIDH concluyó que ante la "crisis de graves violaciones de derechos humanos que atraviesa México [...] el gran desafío del Estado mexicano radica en romper el ciclo de impunidad". ${ }^{42}$

La CIDH también monitorea la situación de los derechos humanos en los países de América mediante la celebración de “audiencias públicas”. Éstas, celebradas en el marco de las sesiones regulares de la Comisión, son generalmente solicitadas por organizaciones de la sociedad civil (OSC), pero también el Estado puede requerirlas a los miembros de la CIDH. En ellas, participan tanto las ocs peticionarias, como representantes del Estado, los cuales suelen protagonizar ante los comisionados una especie de debate sobre los méritos de sus visiones (generalmente opuestas) de la situación de los derechos humanos en el país. Entre 2013 y 2017, se celebraron un total de 44 audiencias temáticas sobre México, lo cual demuestra que la agenda mexicana se mantuvo muy presente entre los temas de interés de la CiDH a lo largo de todo el sexenio.

Tensiones entre el gobierno y los órganos internacionales de derechos humanos

Una característica central del periodo fueron las álgidas y repetidas tensiones entre el gobierno de EPN y los órganos internacionales de derechos humanos. Las dificultades en la relación con la CIDH y el GIEI destacaron en los medios de comunicación aunque, como veremos en esta sección, no fueron las únicas. El GIEI, integrado por cinco expertos, fue establecido por la CIDH a solicitud del gobierno mexicano, como resultado de un acuerdo con los familiares de los estu-

${ }^{41}$ Comisión Interamericana de Derechos Humanos, CiDH, Informe sobre la..., op. cit.Véase, también, A. Anaya Muñoz, El país bajo presión..., op. cit.

42 Ibid., p. 231. 
diantes desaparecidos de Ayotzinapa. ${ }^{43}$ La aceptación del establecimiento del GIEI (en noviembre de 2014) y el pago de los gastos relacionados con sus labores por parte del gobierno mexicano sugirieron en su momento una apertura de México al escrutinio internacional. Sin embargo, al poco tiempo comenzaron a volverse evidentes fuertes tensiones. En abril de 2016, el gobierno decidió no prorrogar la vigencia del acuerdo de asistencia técnica correspondiente, terminando así el mandato del GIEI. ${ }^{44}$ La CIDH lamentó "profundamente" esta decisión del gobierno, a pesar de que, según la propia comisión, los objetivos que se plantearon para el grupo aún no se habían alcanzado. ${ }^{45}$ Como ya se señaló, los miembros del GIEI realizaron un buen número de visitas al país, en las cuales interactuaron de manera directa e intensa con los familiares de los jóvenes desaparecidos y sus representantes, con osc y con agentes del Estado. Los resultados de su investigación y análisis se plasmaron en dos extensos informes, en los que cuestionaron de manera severa la actuación de las distintas fuerzas de seguridad mexicanas ante la agresión a los normalistas ${ }^{46}$ y sobre todo la manera en que la Procuraduría General de la República (PGR) condujo la investigación.

${ }^{43}$ Alejandro Anaya Muñoz, entrevista con Santiago Aguirre Espinosa, subdirector del Centro de Derechos Humanos Miguel Agustín Pro Juárez, 24 de mayo de 2018.

${ }^{44}$ Loc. cit.

${ }^{45}$ Comisión Interamericana de Derechos Humanos, CIDH, "CIDH concluye el $157^{\circ}$ Periodo de sesiones", comunicado de prensa 049/16, 15 de abril de 2016. Ante la terminación del mandato del GIEI, la CIDH determinó establecer un "mecanismo especial de seguimiento, hasta lograr el cumplimiento de los objetivos y recomendaciones establecidos tanto en la medida cautelar como en los informes del GIEI".

${ }^{46}$ En este sentido, por ejemplo, el GIEI concluyó que los "escenarios de violencia de esa noche muestran un panorama de indefensión de las víctimas frente a los agresores. Ello no sólo por el hecho de que se trataba de policía municipal, sino porque ninguna otra fuerza del Estado que estaba teniendo conocimiento de los hechos [o] fue testigo [de ellos] actuó en protección de los normalistas" (Grupo Interdisciplinario de Expertos Independientes, "Informe Ayotzinapa", op. cit.) 
Como es bien conocido, el GIEI desacreditó la versión oficial o la llamada "verdad histórica" planteada por la PGR, la cual proponía que los estudiantes habían sido asesinados y posteriormente incinerados en el basurero de Cocula por una banda del crimen organizado. ${ }^{47}$ Por otro lado, tras la publicación en 2015 del ya mencionado informe de país elaborado por la CIDH, el gobierno calificó la metodología del informe como "sesgada". 48

El mismo tipo de reacción gubernamental se dio durante todo 2015 ante los informes críticos de otros órganos o mandatos internacionales de derechos humanos, particularmente los del Comité contra la Desaparición Forzada y el Relator especial contra la tortura de la ONU. En su informe de observaciones que data de finales de 2015, el Comité contra la Desaparición Forzada señaló "un contexto de desapariciones generalizadas en gran parte del territorio del Estado parte, muchas de las cuales podrían calificarse como desapariciones forzadas [...]. El grave caso de los 43 estudiantes [de Ayotzinapa] ilustra los serios desafíos que enfrenta el Estado parte en materia de prevención, investigación y sanción de las desapariciones forzadas y búsqueda de las personas desaparecidas". ${ }^{49}$

El gobierno de EPN reaccionó argumentando que las observaciones del Comité "no correspondían con la realidad". ${ }^{50}$ Una reacción similar se dio con respecto al informe del relator especial contra la tortura: el gobierno mexicano nunca quiso aceptar que la tortura en México era una práctica "generalizada”, como lo había planteado el Relator. ${ }^{51}$ Más aún,

${ }^{47}$ Véase Grupo Interdisciplinario de Expertos Independientes, GIEI, "Informe Ayotzinapa II", op. cit.

${ }^{48}$ O. Guzmán Vergara, "México y su política exterior...", op. cit.

${ }^{49}$ Naciones Unidas, Comité contra la Desaparición Forzada, Observaciones finales..., op. cit., párr. 10.

${ }^{50}$ Cit. por O. Guzmán Vergara, "México y su política exterior...", op. cit.

${ }^{51}$ Naciones Unidas, Comité contra la Desaparición Forzada, op. cit.; A. Anaya Muñoz, entrevista con Erasmo Lara..., op. cit. 
aplicando la táctica de "matar al mensajero" (un tipo extremo de negación), el gobierno mexicano cuestionó la integridad y las motivaciones del Relator (el prestigiado activista y académico argentino Juan Méndez) ${ }^{52}$ En esta misma línea, en un discurso inusitado durante el 31 periodo de sesiones del CDH, el subsecretario para Asuntos Multilaterales y Derechos Humanos de la Secretaría de Relaciones Exteriores cuestionó la solidez, objetividad, veracidad, profesionalismo y apego al derecho internacional de las recomendaciones elaboradas por los mecanismos de derechos humanos de la onu. ${ }^{53}$ Finalmente, hacia el final del sexenio, en 2018, se dio un nuevo episodio de tensión y descalificaciones del reporte titulado Doble injusticia. Informe sobre violaciones de derechos humanos en la investigación del caso Ayotzinapa, que se publicó en marzo de 2018 por la representación en México de la Oficina del Alto Comisionado de las Naciones Unidas para los Derechos Humanos (OACNUDH). ${ }^{54}$ En un documento presentado en Ginebra, Suiza, sede de la oACNUDH y de toda la estructura de derechos humanos de la ONU, el gobierno mexicano reprochó a esta oficina el haberse extralimitado

52 A. Anaya Muñoz, entrevista con Santiago Corcuera..., op. cit.

${ }^{53}$ Secretaría de Relaciones Exteriores, SRE, "Intervención del subsecretario para Asuntos Multilaterales y Derechos Humanos, emb. Miguel Ruiz Cabañas, segmento de alto nivel del $31^{\circ}$ periodo de sesiones. Consejo de Derechos Humanos", 29 de febrero de 2016, https://mision.sre. gob.mx/oi/images/pdf/codh31_intervencion_mrc.pdf (consulta del 9 de mayo de 2018). Véase, también, O. Guzmán Vergara, "México y su política exterior...", op. cit.; Santiago Corcuera, "Ante la negación, el ataque", El Universal, 12 de marzo de 2016 (sec. Opinión), http://www.elu niversal.com.mx/entrada-de-opinion/articulo/santiago-corcuera/na cion/2016/03/12/ante-la-negacion-el-ataque (consulta del 9 de mayo de 2018).

${ }^{54}$ Naciones Unidas, Oficina del Alto Comisionado de las Naciones Unidas para los Derechos Humanos, OACNUdH, "Doble injusticia. Informe sobre violaciones de derechos humanos en la investigación del caso Ayotzinapa", 15 de marzo de 2018, https://www.ohchr.org/Documents/ Countries/MX/OHCHRMexicoReportMarch2018_SP.pdf (consulta del 12 de junio de 2018). 
en sus funciones y cuestionó de nueva cuenta la metodología y los hallazgos del informe. ${ }^{55}$

Durante los dos sexenios previos, el gobierno no había impugnado de manera tan directa, y sobre todo en un tono tan duro, los informes de los órganos internacionales de derechos humanos. ${ }^{56} \mathrm{Si}$ bien el gobierno de Felipe Calderón se mostró muy incómodo ante la crítica externa en algunas ocasiones, las respuestas en tono de negación se llevaron a un extremo "desproporcionado" durante la administración de EPN. ${ }^{57}$

De acuerdo con un funcionario de la cancillería, en efecto, la relación de México con los órganos internacionales de derechos humanos no estuvo "exenta de dificultades" durante el periodo. Sin embargo, desde su perspectiva, los "episodios complicados" no deben entenderse como manifestaciones de una estrategia de negación, sino como resultado de "la profundidad y madurez del diálogo", como parte de "una relación [...] más franca, madura con los mecanismos, en la que se vale decir cuando no estás de acuerdo en alguno u otro tema", si bien a ambas partes les hace falta "aprender a no coincidir en algunos temas [...] aprender cómo no estar de acuerdo [...] y cómo plantearlo". ${ }^{58}$ En suma, podemos observar señales de que el gobierno reaccionó con lo que los estudios especializados identifican como estrategias de negación, ${ }^{59}$ sugiriendo un cambio parcial en la política exterior de derechos humanos con respecto a los dos sexenios anteriores.

55 Secretaría de Relaciones Exteriores, SRE, "Postura del gobierno de México con respecto al informe: 'Doble injusticia' ", 7 de mayo de 2018, https://www.gob.mx/sre/documentos/postura-del-gobierno-de-mexicocon-respecto-al-informe-doble-injusticia-sobre-el-caso-ayotzinapa (consulta del 9 de mayo de 2018).

${ }^{56}$ A. Anaya Muñoz, "Política exterior y derechos humanos...", op. cit.; A. Anaya Muñoz y N. Saltalamacchia Ziccardi, "México y la reforma...", op. cit., pp. 52-55.

${ }^{57}$ A. Anaya Muñoz, entrevista con Santiago Corcuera..., op. cit.

58 A. Anaya Muñoz, entrevista con Erasmo Lara..., op. cit.

${ }^{59}$ S. Cohen, "Government Responses...", op. cit. 


\section{Conclusiones}

Este artículo demuestra que la política exterior de México en materia de derechos humanos durante el sexenio de EPN se caracterizó por ser contradictoria: al tiempo que se hallan importantes señales de continuidad con la política de apertura al escrutinio internacional, se observa también reacciones que sugieren una política de negación o incluso un intento por volver a un enfoque basado en el predominio de las nociones de soberanía y no intervención. De manera paralela a las acciones de política exterior que sugieren una conducta de "buen miembro del club", se han enviado mensajes en sentido contrario, que sugieren una identidad soberanista o que muestran un Estado que se siente incómodo e irritado ante la "injerencia" internacional en la solución de sus problemas y retos internos. Esto sugiere tensiones identitarias en el ámbito de la política exterior de derechos humanos de México. ¿Cómo "nos ven” o, mejor dicho, cómo "nos entienden" desde afuera: como un miembro ejemplar del club o como uno que ya no está seguro de querer jugar?

Por otro lado, también se ponen sobre la mesa interrogantes de corte explicativo. En concreto, preguntarnos si el gobierno de EPN intentó dar marcha atrás a la política de apertura y regresar al modelo basado en el principio de soberanía y no intervención. De ser así, ¿cómo podemos explicar esta tendencia soberanista? ¿Es acaso el “ADN priista”? ¿Es la nostalgia por un pasado sin este tipo de contrapesos internacionales ante una manera particular de gobernar? $\mathrm{O}$, ¿es que hubo presiones al propio gobierno de parte de grupos o sectores internos particularmente poderosos con una agenda contraria a los derechos humanos? Por otro lado, en su caso, ¿por qué el gobierno de EPN no logró "volver al pasado" plenamente y cancelar la política de apertura? ¿Lo impidieron los "candados externos" característicos de la política de apertura? ${ }^{60}{ }^{\circ} \mathrm{O}$ es que ninguna de estas preguntas y sus res-

${ }^{60}$ A. Anaya Muñoz, "Transnational and domestic processes...", op. cit. 
pectivas hipótesis realmente tienen sentido porque no estamos ante intentos de negación o de volver al pasado, sino ante desacuerdos "naturales", válidos y legítimos entre dos partes en una relación madura, en la que se vale disentir y de vez en cuando enojarse entre sí? La respuesta a todas estas preguntas va más allá del objetivo y alcance de este artículo. Por lo pronto, la descripción que se ofrece las pone sobre la mesa de manera inevitable, esperando que provoquen futuros esfuerzos de investigación, orientados a explicar y entender las contradicciones, la continuidad y el cambio en la política exterior de México en materia de derechos humanos.

\section{Bibliografía}

Anaya Muñoz, Alejandro, Derechos humanos en y desde las relaciones internacionales, Ciudad de México, CIDE, 2014.

Anaya Muñoz, Alejandro, El país bajo presión. Debatiendo el papel del escrutinio internacional de derechos humanos sobre México, México, CIDE, 2012.

Anaya Muñoz, Alejandro, entrevista con Erasmo Lara Cabrera, director general de Derechos Humanos y Democracia de la Secretaría de Relaciones Exteriores, 18 de mayo de 2018.

AnAya Muñoz, Alejandro, entrevista con Santiago Aguirre Espinosa, subdirector del Centro de Derechos Humanos Miguel Agustín Pro Juárez, 24 de mayo de 2018.

Anaya Muñoz, Alejandro, entrevista con Santiago Corcuera Cabezut, 7 de mayo de 2018.

Anaya Muñoz, Alejandro, "Política exterior y derechos humanos durante el gobierno de Felipe Calderón”, Foro Internacional, vol. 53, núms. 3-4 (2013), pp. 771-793.

Anaya Muñoz, Alejandro, "Transnational and domestic processes in the definition of human rights policies in Mexico", Human Rights Quarterly, Vol. 31, núm. 1 (2009), pp. 35-58.

Anaya MuÑoz, Alejandro y Natalia Saltalamacchia Ziccardi, "México y la reforma al Sistema Interamericano de Derechos Humanos”, Pensamiento Propio, núm. 38 (2013), pp. 49-88. 
Cohen, Stanley, "Government Responses to Human Rights Reports: Claims, Denials, and Counterclaims", Human Rights Quarterly, vol. 18, núm. 3 (1996), pp. 517-543.

Comisión Interamericana de Derechos Humanos, CIDH, Ayotzinapa (sitio de internet), http://www.oas.org/es/cidh/actividades/giei.asp (consulta del 24 de abril de 2018).

Comisión Interamericana de Derechos Humanos, CIDH, Informes de país (sitio de internet), http://www.oas.org/es/cidh/informes/pais.asp (consulta del 21 de abril de 2018).

Comisión Interamericana de Derechos Humanos, CIDH, “CIDH concluye el $157^{\circ}$ periodo de sesiones", comunicado de prensa 049/16, 15 de abril de 2016.

Comisión Interamericana de Derechos Humanos, CIDH, Informe sobre la situación de los derechos humanos en México. OEA/Ser.L/V/ II. Doc. 44/15, 31 diciembre 2015, http:/ / www.oas.org/es/ cidh/informes/pdfs/mexico2016-es.pdf

Corte Interamericana de Derechos Humanos, CoIdH, Informe No. 15/16. Petición 1171-09. Informe de Solución Amistosa. Ananías Laparra Martínez y Familiares. México, OEA/Ser.L/ V/II.157 Doc.19, 14 de abril de 2016, https://www.oas.org/ es/cidh/decisiones/2016/MXSA1171-09ES.pdf

Corte Interamericana de Derechos Humanos, CoIDH, Informe No. 51/13. Caso 12.551. Paloma Angélica Escobar Ledezma y Otros. Fondo (Publicación) México, 12 de julio de 2013, https:/ /www. oas.org/es/cidh/docs/anual/2013/docs-es/62.MX PU12551 ES.pdf

Corte Interamericana de Derechos Humanos, CoIdH, Informe No. 80/15. Caso 12.689. Informe de Fondo (Publicación) J.S.C.H y M.G.S México, OEA/Ser.L/V/II.156 Doc. 33, 28 de octubre de 2015, https://www.oas.org/es/cidh/decisiones/ 2015/mxPU12689Es.pdf

Corte Interamericana de Derechos Humanos, CoIdH, Informe 51/16. Caso 11.564. Informe de Admisibilidad y Fondo (Publicación). Gilberto Jiménez Hernández y Otros (La Grandeza). México, OEA/Ser.L/V/II.159 Doc. 60, 30 de noviembre de 2016, https://www.oas.org/es/cidh/decisiones/2016/MXPU 11564ES.docx 
Corte Interamericana de Derechos Humanos, CoIdH, Informe No. 138/11. Caso 12.288. Juan García Cruz y Santiago Sánchez Silvestre. Fondo. México, 31 de octubre de 2011, https://www. oas.org/es/cidh/decisiones/corte/12.288FondoEsp.doc

Corte Interamericana de Derechos Humanos, CoIdH, Informe No. 3/16. Caso 12.916. Informe de Fondo. Nitza Paola Alvarado Espinoza, Rocío Irene Alvarado Reyes, José Ángel Alvarado Herrera y Otros. México, OEA/Ser.L/V/II.157 Doc. 7, 13 de abril de 2016, https://www.oas.org/es/cidh/decisio nes/cor te /2016/12916FondoEs.pdf

Corte Interamericana de Derechos Humanos, CoIDH, Informe No.

74/15. Caso 12.846. Informe de Fondo. Mariana Selvas Gómez y Otras. México, OEA/Ser.L/V/II.156 Doc. 27, 28 octubre de 2015, https://www.oas.org/es/cidh/decisiones/corte/2016/1 2846FondoEs.pdf

Corte Interamericana de Derechos Humanos, CoidH, Caso García Cruz y Sánchez Silvestre vs. Estados Unidos Mexicanos. Sentencia de 26 de noviembre de 2013 (Fondo, Reparaciones y Costas), http://www.corteidh.or.cr/docs/casos/articulos/seriec_2 73_esp.pdf

Corte Interamericana de Derechos Humanos, CoidH, Caso Trueba Arciniega y Otros vs. México. Sentencia de 27 de noviembre de 2018, http://www.corteidh.or.cr/docs/casos/articulos/seriec_369_esp.pdf

Corte Interamericana de Derechos Humanos, CoIDH, Caso Alvarado Espinoza y Otros vs. México. Sentencia de 28 de noviembre de 2018 (Fondo, Reparaciones y Costas), http://www.corteidh.or.cr/docs/casos/articulos/seriec_370_esp.pdf

Corte Interamericana de Derechos Humanos, CoidH, Caso Mujeres Víctimas de Tortura Sexual en Atenco vs. México. Sentencia de 28 de noviembre de 2018 (Excepción Preliminar, Fondo, Reparaciones y Costas), http:/ /www.corteidh.or.cr/docs/casos/ articulos/seriec_371_esp.pdf

Corcuera, Santiago, “Ante la negación, el ataque”, El Universal, 12 de marzo de 2016 (sec. Opinión), http://www.eluniversal. com.mx/entrada-de-opinion/articulo/santiago-corcuera/na 
cion/2016/03/12/ante-la-negacion-el-ataque (consulta del 9 de mayo de 2018).

Grupo Interdisciplinario de Expertos Independientes, GIEI, "Informe Ayotzinapa. Investigación y primeras conclusiones de las desapariciones y homicidios de los normalistas de Ayotzinapa",s/f",https://drive.google.com/file/d/0B1ChdondilaHNz FHaEs3azQ4Tm8/view (consulta del 20 de noviembre 2018).

Grupo Interdisciplinario de Expertos Independientes, GIEI, "Informe Ayotzinapa II. Avances y nuevas conclusiones sobre la investigación, búsqueda y atención a las víctimas", s/f, https:/ / drive.google.com/file/d/0B3wuz7S3S9urNFFlZUNMSld QUlk/view, (consulta del 20 de noviembre 2018).

Guzmán Vergara, Olga, "México y su política exterior de negación. La defensa de derechos humanos en un contexto de retrocesos", SUR. Revista internacional de derechos humanos, vol. 14, núm. 26 (2017), pp. 89-102.

Lara Cabrera, Erasmo A., "Política exterior multilateral, derechos humanos y grupos en situación de vulnerabilidad", Revista Mexicana de Política Exterior, núm. 110 (2017), pp. 97-117.

Lauren, Paul Gordon, The Evolution of International Human Rights. Visions Seen, Philadelphia, University of Pennsylvania Press, $2^{\text {a }}$ ed., 2003.

Naciones Unidas, Asamblea General, Resolución 60/251, Consejo de Derechos Humanos (A/RES/60/251), 3 de abril de 2006

Naciones Unidas, Consejo de Derechos Humanos, Informe del Relator Especial sobre la tortura y otros tratos o penas crueles, inhumanos o degradantes, Juan E. Méndez. Adición. Misión a México (A/HRC/ 28/68/Add.3), 29 de diciembre de 2014.

Naciones Unidas, Consejo de Derechos Humanos, Resolución 5/1, 18 de junio de 2007.

Naciones Unidas, Comité contra la Desaparición Forzada, Observaciones finales sobre el informe presentado por México en virtud del artículo 29, párrafo 1, de la Convención (CED/C/MEX/CO/1), 5 de marzo de 2015.

Naciones Unidas, Oficina del Alto Comisionado de las Naciones Unidas para los Derechos Humanos, "Doble injusticia. Informe sobre violaciones de derechos humanos en la investigación 
del caso Ayotzinapa", 15 de marzo de 2018, https://www.oh chr.org/Documents/Countries/MX/OHCHRMexicoReportMarch2018_SP.pdf (consulta del 12 de junio de 2018).

"Recomendaciones internacionales a México en materia de derechos humanos" (sitio de internet), www.recomendaciones dh.mx

Saltalamacchia Ziccardi, Natalia y Ana Covarrubias Velasco, "La trayectoria de los derechos humanos en la política exterior de México (1945-2006)", en Natalia Saltalamacchia Ziccardi y Ana Covarrubias Velasco (eds.), Derechos humanos en política exterior. Seis casos latinoamericanos, Ciudad de México, IтAм / Miguel Ángel Porrúa, 2011, pp. 166-176.

Secretaría de Relaciones Exteriores, sRe, "Comunicado sobre Venezuela", comunicado núm. 183, 3 de mayo de 2017, https:/ / www.gob.mx/sre/prensa/comunicado-sobre-venezuela-1056 11 (consulta del 11 de junio de 2018).

Secretaría de Relaciones Exteriores, sRe, "Cumbre de las Américas. Declaración sobre Venezuela", 16 de abril de 2018, https://www.gob.mx/sre/prensa/cumbre-de-las-americas-de claracion-sobre-venezuela (consulta del 11 de junio de 2018).

Secretaría de Relaciones Exteriores, SRE, "Intervención del subsecretario para Asuntos Multilaterales y Derechos Humanos, emb. Miguel Ruiz Cabañas, segmento de alto nivel del $31^{\circ}$ periodo de sesiones. Consejo de Derechos Humanos", 29 de febrero de 2016, https://mision.sre.gob.mx/oi/images/pdf/codh31_in tervencion_mrc.pdf (consulta del 9 de mayo de 2018).

Secretaría de Relaciones Exteriores, SRE, "México llama a consultas a su embajadora en Venezuela”, comunicado núm. 147, 21 de mayo de 2018, https://www.gob.mx/sre/prensa/mexicollama-a-consultas-a-su-embajadora-en-venezuela (consulta del 11 de junio de 2018).

Secretaría de Relaciones Exteriores, sRe, "Postura del gobierno de México con respecto al informe: 'Doble injusticia' ", 7 de mayo de 2018 https://www.gob.mx/sre/documentos/postura-delgobierno-de-mexico-con-respecto-al-informe-doble-injusticiasobre-el-caso-ayotzinapa (consulta del 9 de mayo de 2018). 
Secretaría de Relaciones Exteriores, SRE, Primer informe de labores 2012-2013, Ciudad de México, Secretaría de Relaciones Exteriores, 2013.

Secretaría de Relaciones Exteriores, sRE, "Situación en Venezuela", comunicado núm. 252, 28 de junio de 2017, https:/ / www.gob. $\mathrm{mx} / \mathrm{sre} / \mathrm{prensa} /$ situacion-en-venezuela?idiom=es (consulta del 11 de junio de 2018). 
